Serafina Martins

Universidade de Lisboa serafinamartins@sapo.pt

\title{
A crise económica na literatura portuguesa recente: casos de 2011 e 2013
}

\section{Resumo:}

Neste trabalho, estudam-se dois romances cujo assunto principal é a crise económica iniciada em 2008 e reveladores das consequências sociais e emocionais desta crise. Em $A$ instalação do medo, esta emoção vence a protagonista; em Índice médio de felicidade a esperança e o altruísmo permitem uma pequena revolução. São, deste modo, exemplos de como a crise afectou a arte e ilustram um processo, ainda em curso, de transformação da literatura portuguesa.

Palavras-chave: crise económica, sociedade, efeitos, literatura portuguesa, transformação

\section{Abstract:}

\section{The Economic Crisis in Recent Portuguese Literature: Cases of 2011 and} 2013

This essay aims to analyse $A$ instalação do medo e Índice médio de felicidade, two novels about the social and emotional effects of the most recent economic crisis, which began in 2008. Both are examples of how the Portuguese art was influenced by that crisis as well as of some relevant transformations occurring in Portuguese contemporary literature.

Keywords: economical crisis, society, effects, Portuguese literature, transformation 


\section{Ponto de situação}

Em Setembro de 2008, deu-se um importantíssimo acontecimento histórico do século XXI com a queda do Lehman Brothers, na sequência da atribuição de crédito de alto risco, o chamado subprime. Um mercado liberto de regras anti-risco, no pressuposto de que bastariam hipotéticos mecanismos espontâneos de auto-regulação, bem como a dinâmica global dos sistemas financeiros levaram a uma crise bancária de enormes proporções. Nesse ano de 2008 , o cidadão português não se preocupou extraordinariamente com estas informações nem, na verdade, essa era uma grande preocupação na União Europeia, segundo declarações de Fernando Teixeira dos Santos, então ministro das finanças de Portugal. No entanto, a rapidez dos acontecimentos, no plano mundial e nacional, levou a que no dia 2 de Novembro desse ano o ministro e o governador do Banco de Portugal comunicassem a decisão, tomada em conselho de ministros, de nacionalizar o Banco Português de Negócios justamente devido ao risco que representava para a totalidade da banca portuguesa. Usavam-se na altura metáforas como "contaminação", "activos tóxicos", "rastilho", "incêndio", etc.

Para o cidadão comum, que pouco ou nada sabia de finanças, foi um acontecimento que provocou estranheza, em particular nas gerações que se lembravam das nacionalizações ocorridas logo a seguir ao a 25 de Abril de 1974. As razões político-ideológicas destas nacionalizações não coincidiam com as circunstâncias de 2008; foi necessário compreendê-las integrando-as num contexto geográfico muito mais vasto, num plano intelectual em que a política se cruzava agora com o sistema financeiro mundial e em que o benefício e o prejuízo, sobretudo o prejuízo, se disseminavam de forma descontrolada. A auto-regulação dos mercados e, com ela, a ideia neoliberal da inferiorização do papel do Estado tinham redundado numa crise económica mais grave do que a de 1929. Foi preciso também aprender uma nova linguagem, que não importa agora reproduzir. Finalmente, e no que respeita a compreensão e aprendizagem, foi necessário debater, por vezes só nas consciências individuais, uma estranha moralidade, cujo centro estava na imputação de responsabilidades não às estruturas de 
topo, mas a todos nós, todos os que, por exemplo, tinham usado créditos bancários. Ideias inesquecíveis da época diziam que éramos todos responsáveis - ipsis verbis - e que, ipsis verbis, os portugueses viviam acima das suas possibilidades. Daí para a conclusão aparentemente lógica de que vivíamos à custa da Europa rica, como foi dito por figuras de alta responsabilidade da União Europeia, foi um pequeno salto.

A crise económica gerou igualmente, nos seus primórdios, uma crise identitária colectiva, resultante da incorporação das ideias culpabilizadoras e da fragilização pessoal que estas acarretam, na medida em que geram medo e diminuem a capacidade de reacção. Estudos na área da psicologia de grupos mostram que o chamado "contágio emocional", ou seja, a comunicação e disseminação de estados afectivos são fundamentais para a organização de estruturas humanas grupais. "There is abundant evidence that individuals emotionally converge when exposed to affective stimuli", escrevem Janice R. Kelly, Nicole E. Ianonne e Megan K. McCarty (2016: 183). As frases culpabilizadoras antes referidas, imbuídas de uma carga emocional muito poderosa do ponto de vista argumentativo, disseminaram-se no país como verdades que, por isso mesmo, não era necessário comprovar. Com maior ou menor consciência do que estava a ser feito, com maior ou menor dolo por parte de quem as pronunciava, o facto é que os portugueses foram expostos a um processo de difusão de ideias morais com efeitos emocionalmente negativos.

As duas obras de que aqui se vai falar constituem exemplos da forma como a literatura portuguesa reagiu perante os acontecimentos traumáticos da crise económica e as emoções provocadas, uma reacção que foi amplamente partilhada noutras artes. É o caso particularmente notório do cinema e do teatro. Em 2011, foi representada uma peça pioneira sobre a degradação social provocada pela crise intitulada $J a ́$ passaram quantos anos, perguntou ele, de Rui Pina Coelho, na qual as personagens, ainda relativamente jovens, verbalizam a sua desilusão com a falta de perspetivas de futuro; diga-se que entre 18 e 23 de Setembro de 2018 esteve em cena, num prédio junto ao Teatro Carlos Alberto (no Porto,) uma peça de Regina Guimarães, Imóvel, sobre os dilemas de personagens nos 40 anos de idade, igualmente 
desapontadas com a existência precária que o mundo actual lhes reserva e com uma crise política onde por diferentes formas se insinua a desconfiança sobre a viabilidade da democracia.

As duas obras escolhidas, além de tematizarem os factos que mais perturbaram, e perturbam ainda, a sociedade portuguesa na segunda década do século XXI, têm em comum o interesse pelos efeitos emocionais supervenientes. Por ordem cronológica, são essas obras os romances A instalação do medo, de Rui Zink (2012) e Índice médio de felicidade, de David Machado (2013). Numa altura em que ainda é difícil fazer a destrinça qualitativa dos textos literários sobre a crise económica - dificuldade que resulta de essa literatura estar ainda a ser produzida e de não terem sido feitos estudos de balanço - nesta altura, dizia, o mérito destes romances está já suficientemente reconhecido. A instalação do medo tem três edições portuguesas e está traduzido, no que foi possível apurar, para alemão, romeno e francês. Em França, aliás, recebeu em 2017 o prémio Les Utopiales, festival internacional de ficção científica; no mesmo ano, o realizador Ricardo Leite adaptou a obra para o cinema com uma curta metragem onde manteve o título, tendo recebido em 2017 o prémio Sophia de Estudante da Academia Portuguesa de Cinema. Índice fédio de felicidade, por sua vez, recebeu em 2015 o Prémio da União Europeia para a Literatura e integrou a longlist do International Dublin Literary Prime de 2018, o qual foi atribuído a Mike McCormack. O livro tem, pelo menos, tradução inglesa francesa e búlgara; em 2016 foi adaptado ao cinema pelo realizador Joaquim Leitão.

\section{Medo}

O enredo mínimo de $A$ instalação do medo é relativamente simples. Uma mulher está na sua casa apenas com o filho quando tocam à campainha. O facto de ela perguntar a si mesma se "serão eles?" (9; itál. orig.) permite ao leitor compreender de imediato uma expectativa negativa na figura feminina, evidente na ansiedade que o toque da campainha the provoca e, mais ainda, por ir acordar o menino para o esconder na casa de banho, pedindo-lhe silêncio - "Como já fizemos das 
outras vezes" (ibid.), diz-lhe. Este é o assunto do primeiro capítulo do livro, muito breve, como são praticamente todos os que o compõem. No segundo, surgem na narrativa as duas outras personagens principais, dois homens, um deles engravatado e bem-falante, como se dirá inúmeras vezes no romance, outro de fato de macaco, mais deselegante e rude, que dizem vir instalar o medo com a naturalidade de quem faz uma declaração normal na vida normal. Perante a hesitação da mulher, apenas insinuada, o homem do fato, entre argumentos mais sibilinos, cita as palavras de uma ordem governamental, a Directiva n. ${ }^{\circ} 359 / 13$. Portaria 8: "Todos os lares devem ter o medo instalado num prazo de 120 dias" (13). O que se segue no livro, continuando a síntese desse enredo mínimo, é a aplicação da directiva, primeiro com a instalação, feita pelo operário, e depois com a demonstração, como se se fizesse uma espécie de teste de qualidade. "Instalação e "demonstração" constituem, justamente, os termos com que Rui Zink designou as duas partes intermédias e principais do texto. Nesta divisão e nestes nomes, de natureza paratextual, encontramos um primeiro sintoma da banalização de circunstâncias absurdas - apontadas no título do romance, cujo sentido é literal -, um processo constante na obra e logo de início desvendado. $\mathrm{O}$ efeito dessa banalização é previsível: o esbatimento das diferenças qualitativas e éticas entre o normal e o absurdo, o que contribui para a aceitação dos acontecimentos não razoáveis que proliferam na narrativa dirigidos a uma personagem isolada, a mulher, mas que são representativos do estado das coisas no país onde a história acontece. Não é difícil, aliás, chegar à conclusão de que instalar o medo está próximo de instalar um electrodoméstico ou um engenho tecnológico que ocupa um espaço material insignificante, mas que, em contrapartida, invade profundamente o espaço mental, alterando as consciências. Muito hábil a usar performances discursivas tipificadas, Rui Zink escreveu o seu romance trazendo características de um episódio de vendas que são feitas nas casas particulares (um aspirador milagroso, caixinhas de plástico, robôs de cozinha...), sublinhando deste modo a mecanização do que é feito por Carlos (o engravatado) e Sousa (o que usa fato-macaco). 
Podemos afirmar que o empreendimento central dos dois homens consiste precisamente em transformar a mulher à sua imagem, tornando-a crente nos seus axiomas, fidelizada, digamos assim, pelos métodos usados na demonstração. Não existe na obra quem faça um juízo crítico total, não há um olhar puro, ou simples, que estabeleça as suas implicações. Contudo, esse juízo pressupõe-se, feito um pouco pelo medo que a mulher sente enquanto pessoa injuriada e como resultado, sobretudo, de poderosos significados implícitos obtidos através da ironia e de mimetismos linguísticos. A maior ironia reside, porventura, no facto de ser o medo emocionalmente experimentado pela mulher a sua melhor defesa contra a liturgia que os dois homens ali representam.

Não é por acaso que em textos breves, no âmbito da crítica literária de divulgação, se fale deste texto como uma obra kafkiana tendo em conta o sistema burocrático que vigora e envolve praticamente todos os passos da narrativa. Burocracia levada, claro, às últimas instâncias, sublinhando o autor as tintas da desumanização que este "processo" reinventado acarreta. Embora saibamos que a acção decorre em Portugal, poucos são os dados que delimitam o enredo, dando explicações, por exemplo, sobre a casa onde tudo acontece ou a identidade das personagens - característica agudizada na parte final, onde há um twist à maneira da cinematografia americana de grande circulação, uma das imensas referências à cultura pop que Rui Zink transportou para seu texto e que, no meu entender, o leitor descobre com gosto. No fundo, não há aquilo a que é comum chamar cor local, nem há também extraordinários recortes identitários; o escritor realizou um compromisso entre um modelo de escrita desenvolvido segundo a forma intelectual da globalização - onde escasseiam os traços pitorescos, habitual na literatura portuguesa contemporânea - e um outro, mais tradicional, onde existem particularidades ambientais e humanas frequentes na literatura da crise económica.

Embora saibamos alguma coisa sobre os homens que vêm instalar o medo, esse saber é rarefeito, apresentado de acordo com as possibilidades que a percepção narrativa admite. O narrador externo não tem capacidade de informar, o foco de percepção é não raro o das personagens, há longos excertos numa primeira pessoa cuja identidade 
se desconhece e, principalmente, predominam diálogos que criam um híbrido de texto narrativo e texto dramático. Assim, as personagens são aquilo que fazem e, sobretudo no caso da mulher, aquilo que pensam perante o que está a acontecer. Os dois homens não correspondem a modelos comportamentais humanos, sendo no entanto reconhecíveis no âmbito de universos literários distópicos, a começar justamente pelos kafkianos - uma ideia que é autorizada pela própria obra. Ambos constituem uma realidade dual, um ser biface completando cada um aquilo que falta no outro. O homem do fato chama-se Carlos e o técnico chama-se Sousa, ou seja, tem o apelido que falta à personagem anterior. São o "Carlos Sousa", um daqueles nomes baços da tradição portuguesa, como Manuel Silva, José Pereira, etc. São implacáveis e acríticos no trabalho que têm para fazer, não são criativos, não inventam, não estão sequer a fazer uma experiência. Os axiomas com que iniciam a sua tarefa são reveladores de um exercício rígido e seco no plano moral. O princípio dos princípios na instalação do medo reside precisamente na reprodução de frases axiomáticas cujo valor, ou cuja verdade é sobretudo formal - "O progresso não pára”; “É pelo bem do país".

Os axiomas e a manipulação das emoções constituem a forma inicial e preparatória de os funcionários levarem a cabo a sua missão, procurando desenvolver na mulher sentimentos de culpa que levam à sua concordância com o razoável - não ser contra o bem do país e contra o progresso - e com o absurdo - não ser contra o medo. A condução da mulher para a aceitação de uma ideia irracional resulta, assim, da imposição prepotente de ideias falaciosas, sendo esta a primeira etapa de uma performance que se vai intensificando quase até ao paroxismo e cuja intensidade só diminui mediante a peripécia final, bastante inesperada.

Numa segunda etapa, os sofismas da equipa de instalação dão lugar a acções demonstrativas que começam ainda antes de chegarmos à terceira parte do romance precisamente denominada "Demonstração". A mulher é exposta a diferentes medos, segundo uma tipologia por vezes identificada na obra, enfatizando-se desta maneira o registo burocrático da história. Assim, num primeiro acto da demonstração 
do medo, Carlos e Sousa desfiam verbalmente os referidos animais perigosos: cobras, escorpiões, piranhas. anacondas. Neste momento, a condição biface das personagens é notória; aquilo que dizem surge como uma fala única desdobrada em duas vozes distintas e também por este artifício a narrativa adquire a forma de texto dramático. De maneira bastante proeminente, as referências a dados da cultura pop iniciam uma cadeia que vai adquirindo inúmeros elos à medida que o romance prossegue, com motivações de índole diversíssima. Jogo benévolo com o leitor, incitando à descoberta dessas referências? Citações que são, na verdade, alusões? Homenagem amável a uma cultura que, queiramos ou não, preenche os nossos dias e nos protege de uma certa insularidade? Manifesto político subliminar relativo à pertinência das hierarquias culturais? Creio que estas hipóteses são legítimas e que todas elas casam com o espírito de desconstrução (chamemos-lhe pós-moderno) patente nesta obra notável.

Numa "Nota de autor", que fecha o livro, Rui Zink diz o seguinte: "A intenção inicial era este texto não ter uma única palavra minha. Cheguei no entanto à conclusão, qual Pierre Menard, de que isso seria ao mesmo tempo demasiado fácil e demasiado trabalhoso. Guardei ainda assim alguns fiapos alheios [...] E há mais, que me desobrigo de indiciar" (177). Fez bem em desobrigar-se, pois assim o jogo é mais emotivo e a garantia da exaustividade é inalcançável. Deve-se explicar que no segundo acto da demonstração do medo os tais "fiapos alheios" são praticamente impossíveis de deslindar pois se trata principalmente de um pot-pourri de contos tradicionais, hoje em dia discutivelmente recomendados para a infância. Sofisticando a encenação (também ironicamente) com o uso de um dispositivo multimédia, ao primeiro tipo de medo - o "natural", esclarece-se no romance - sucede o medo atávico (cf. p. 43), que concita a história do Capuchinho Vermelho, de Hansel e Gretel e também do segundo episódio da série cinematográfica Alien, aquele em que Ellen Ripley (Sigourney Weaver) descobre a sua filha afectiva dentro de um casulo feito pela mãe alienígena. Este episódio, aliás, representa com grande mestria a figura das mães protectoras, que não se coíbem de defender os filhos seja de que maneira for. Rui Zink teve a inteligência de aludir a estas mães (neste caso, 
sem “indiciar") integrando essa alusão num excerto onde pontifica uma mãe cruel, de modo a inverter assim o tipo de relação objectal que encontramos no filme.

Os primeiros medos são, no entanto, circundantes do medo maior, o horror, segundo um dos homens, cabendo aqui outras expressões superlativas. O escritor chamou-lhe apropriadamente o medo dos mercados, já que foram estes o centro a partir do qual duros receios, individuais e colectivos, se desenvolveram em Portugal. O romance de que se falará depois, Índice médio de felicidade, muito centrado na realidade local e protagonizado por pessoas do dia-a-dia, é mais concretizador ao relatar uma história de desemprego e a suas consequências na vida de uma família. Como tudo durante esses anos sucedeu muito depressa, em 2013 as consequências da crise financeira eram já notórias; a distopia de Rui Zink, onde o presente, ou a realidade, se compaginam com um universo projectivo que amplia vigorosamente essa realidade, constitui, além de uma obra anterior no plano temporal, uma obra antecedente no plano natural do acontecer.

Dadas as especificidades das ocorrências, compreendem-se melhor as especificidades do discurso presente em $A$ instalação do medo, que, em termos genéricos, ganham forma no âmbito de processos de amplificação e no explorar da figuratividade. Numa página ocupada com sete balões, como os das crianças, os quais, além de serem afins dos que vemos na banda desenhada (lembro que Rui Zink foi co-autor de uma novela gráfica, $A$ arte suprema), encontramos, de modo paradoxal, termos e frases mil e uma vezes repetidos, os clichés de economistas, políticos, etc., de uma natureza tão impressiva que os escritores fizeram delas um produto para a tematização literária da crise. Fala-se de "pessoas mal habituadas", "Egoísmos serôdios", "reformas estruturais". A par dos clichés, ocorreu também, durante esses anos, a divulgação da terminologia especializada dos mercados, em inglês: benchmarking, spread, downsizing, layoff (pp. 80-81). O problema da crise foi também um problema de linguagem, e creio não estar a usar aqui a usar liberdades de interpretação exageradas. No meu entender, quando o efeito de todo o processo for estudado pela História Literária, o levantamento desse aspeto artístico será obrigatório; o Sousa 
oferece-nos mesmo um auxílio para o designar: "O modo como usamos a linguagem" (80). O escritor não esqueceu também as metáforas mais frequentes que foram postas a circular, desde a bucólica "janela de oportunidade" à escatológica "gorduras excedentárias", que consistiam, nomeadamente, no excesso de dinheiro gasto pelo Estado, vindo daí a urgência das famigeradas "reformas estruturais", ou "cortes" também estruturais.

Perante isto, houve de facto a oportunidade de adquirir um saber maior sobre um debate clássico entre a maior ou menor necessidade do Estado na vida dos cidadãos. Há hoje um esclarecimento sobre os aspectos económicos, políticos e sociais de que não dispúnhamos há exactamente dez anos, pois no dia 15 de Setembro de 2018 assinalou-se uma década sobre a falência do Lehman Brothers, tendo a funesta efeméride sido lembrada na comunicação de teor generalista, como o Expresso Online, e também na mais especializada - a revista Exame, dedicada à área da Economia, apresentou no número de Setembro um dossier de 50 páginas sobre as consequências, ainda presentes, desse dia 15, onde faz a sua retrospectiva. No dossier do Expresso Online, foram recolhidos sete artigos e duas entrevistas publicados entre Julho e Agosto, antecedidos por uma introdução não é assinada.

Lendo estes trabalhos, percebemos que há algum consenso em três ideias: a de que Portugal recuperou destes 10 anos, tendo a economia voltado a um estado mais próximo do de 2008; a de que as consequências da crise no plano social ainda não foram corrigidas; finalmente, a de que são necessárias medidas previdentes para evitar outra depressão no futuro próximo. Tendo isto em mente, podemos sugerir que o romance $A$ instalação do medo, além de nos oferecer uma visão hiperbolizada de um processo histórico em 2012 e ainda agora inconcluso, é um aviso, uma sede de premonição muito eficaz tendo em conta, passe o lugar comum, os traços pós-humanos de um mundo que talvez um dia venha ter connosco. Um mundo onde os mercados serão tão avassaladores que já não se pode lutar contra eles; como se diz em jogos de palavras que encontramos na obra, "os mercados são a perfeita sociedade anónima" (53), um "rumor" (ibid.), um "ruído 
branco" (54), com alusões, agora, a Eugénio de Andrade ${ }^{1}$ e Almeida Faria $^{2}$. Carlos faz-se esta pergunta: "Quando iriam perceber que a humanidade acabou?" (165).

Esta podia ser a conclusão deste romance onde as falas dos homens são ruído puro, um teatro operático que nos agride e assusta. A peripécia final dos últimos seis capítulos (cinco da secção "Corolários") mostra-nos o medo instalado no seu ponto perfeito, o de se acreditar na sua necessidade, como sucede aos dois homens. Os seres humanos atingidos pelos monstros, como então ocorre a todas as personagens da narrativa, não são ressarcidos, pois trata-se de um desenlace moderno e ambíguo.

\section{Felicidade}

Lembro palavras anteriores de Janice R. Kelly, Nicole E. Ianonne e Megan K. McCarty sobre a aproximação grupal dos indivíduos em função de estímulos afectivos que recebem para fazer algumas observações sobre Índice médio de felicidade, o romance de David Machado que incide profundamente sobre o problema da crise económica; esta foi entretanto designada como Grande Recessão, termos cuja propriedade é extraordinária e de cuja ciência milhões de portugueses têm conhecimento direto.

Trata-se de um livro encantatório, contado na primeira pessoa por Daniel, figura concebida à imagem de uma geração que estava nos 30 e alguns anos quando tudo aconteceu. Uma geração nascida na década de 80, que tirou proveito do ensino garantido pelo Estado, da existência de emprego garantida no país ao longo da década de 90 e da prodigalidade bancária para comprar património desejavelmente duradouro - por exemplo, uma casa. Daniel e a mulher, Marta, são donos de uma casa comprada com um empréstimo, têm carro, emprego, liberdade financeira e dois filhos: Flor, adolescente, Mateus, pré-adolescente. Têm vidas banais, facilitadas pelo contexto, e um futuro previsível.

\footnotetext{
${ }^{1}$ Poema Coração habitado.

${ }^{2}$ Romance Rumor branco.
} 
Menos comum é o processo usado por David Machado para contar a história. Tratando-se embora de uma narrativa de memórias ficcionais, tem a singularidade de se tratar de uma fala dirigida a Almodôvar, um dos seus dois melhores amigos; ele está preso por ter assaltado uma estação de serviço e não aceita encontrar-se com Daniel quando este tenta visitá-lo na prisão. Esta fala é, pois, uma ficção dentro do romance, tornando viável uma narrativa na segunda pessoa, importante marca distintiva, e a construção de um discurso cuja natureza coloquial propicia, digamos, um encontro com um momento específico de língua portuguesa, aparentemente oral, utilizada por homens urbanos e lisboetas - da classe média; esta constatação é meramente empírica e resulta do reconhecimento de um sociolecto dos dias de hoje, no qual abunda o calão grosseiro e a injúria descontrolada admitida entre pares. David Machado teve a capacidade de criar uma espécie de hiper-realismo linguístico, respeitando a brutalidade do referido sociolecto, apaziguada, no entanto, por um lirismo que completa a voz do narrador e esclarece a sua acção.

Grande parte da história diz respeito a um processo de descalabro cuja síntese em certa medida é perfunctória. Desemprego, dificuldade em pagar a casa, perda da casa, que fica na posse do banco, todo um enredo económico-social banalizado, uma história dos nossos dias. A isso junta-se uma energia dramática causada por uma série de quedas progressivas, na qual Daniel se vê a dormir no carro quase novo, depois no mesmo carro cruelmente queimado por um bando de adolescentes (com intervenção significativa no romance), depois ainda na iminência de dormir na rua. Este facto precipita uma última etapa do texto, narrada nos dois capítulos finais, durante os quais Daniel, os filhos, Vasco (filho de Almodôvar e parte do grupo de adolescentes), Xavier, o amigo de infância deprimido (David Machado desenha um quadro depressivo com grande precisão) e Alípio fazem uma viagem numa carrinha até Genebra para ajudarem uma mulher paraplégica que quer ir ver pela última vez um irmão (internado num hospital de Marselha).

Durante todo a obra, o leitor acompanha as variações, no narrador, desse estranhamente quantificável índice médio de felicidade, criado 
pelo deprimido Xavier. Na vida em descalabro, impõe-se uma linha descendente; na viagem, realista e mágica, surge uma linha ascendente, ambas fáceis de imaginar, pois os níveis são indicados nos títulos de todos os capítulos, com excepção do final. Essas linhas representam uma existência complexa, cujo ponto cimeiro está na destruição de um homem enquanto parte das estruturas sociais que corroem cada indivíduo e em simultâneo se destroem a elas próprias, com as famílias que se separam, com comportamentos chocantes de natureza criminosa (os adolescentes), com a falência de empresas, tudo uma miséria que alastra como as manchas de humidade.

Segundo creio, a obra pode ser interpretada como uma alegoria desta contradição irracional que existe nas forças corruptoras, as quais produzem um campo minado que no final também as põe em risco; a crítica que se faz hoje aos efeitos recessivos da austeridade a que Portugal foi sujeito pela Troika, crítica vinda mesmo da União Europeia e do Fundo Monetário Internacional, clarifica tal irracionalidade. Mais seguramente, a obra consiste num projecto de resistência ao presente e uma preparação do futuro que se esclarece, por um lado, com o papel dado às crianças e jovens e, por outro lado, no desfazer, com a prática de acções, da imaginação distópica sobre o porvir. Esse tipo de imaginação surge ao longo do romance sobretudo nos pensamentos de Daniel e de Flor.

A natureza dessas acções foi já indicada, trata-se da viagem à Suíça. Não se disse ainda que essa viagem é o resultado de um projeto concebido por Almodôvar e que consiste na criação de "uma rede social através da qual pessoas e pessoas que estão dispostas a ajudar podem encontrar-se" (20). É um plano onde colaboram os três amigos, de resposta à crise económica e enquadrado ainda na sua vida relativamente normal.

Sucede, no entanto, que, quando de facto uma mulher se inscreve na rede, a situação de Almodôvar e Daniel é anormal - prisão, no caso do primeiro, Daniel prestes a tornar-se um sem-abrigo - e por isso a viagem deve ser lida ponderando os efeitos nos que nela participam. Trata-se, creio, de estabelecer um novo corpo comunitário depois de desaparecidos todos os que antes respondiam a necessidades 
elementares do mundo moderno, em particular conforto e reconhecimento num plano micro e macrossocial, e às necessidades simbólicas que se elaboram na mente. Um dos aspectos mais cativantes de Índice médio de felicidade está na forma como Daniel se avalia e como racionaliza as ocorrências de que é vítima, movido pela esperança. Esperança à qual se acrescenta um espírito de altruísmo (compaginado num elenco muito vasto de atitudes) onde não aparenta haver desejos de redenção pessoal, porventura egoístas. Uma nova orgânica, constituída por pessoas a sofrerem diferentes formas de degenerescência e, nalguns casos, manifestos desistentes, retira Daniel e os outros do sistema apodrecido e da aflição que então dominavam Portugal.

\section{Conclusão}

Em 2018, Francis Fukuyama publicou Identidades: a exigência da dignidade e a política do ressentimento (logo traduzido em Portugal) onde reflecte sobre os efeitos da Grande Recessão no cenário político contemporâneo dos E.U.A. e da Europa, analisando o fortalecimento das ideologias nacionalistas no âmbito do que chama "políticas identitárias". O enredo de Índice médio de felicidade revela um sentido diferente, até porque não é, stricto sensu, um livro de mensagem política; é, isso sim, uma obra onde os processos de resolução se desenvolvem numa zona intermédia entre o coletivo e o individual em função de uma consciência humanitária - que será talvez a mais universal. Perante a gravidade dos problemas que assolaram Portugal, a exaltação da bondade e da esperança pode parecer ingénua (não tenho essa opinião), mas o romance não é menos eficaz enquanto parte do activismo que as artes portuguesas têm realizado para o nosso sucesso vital.

Sugiro, para concluir, que este e outros textos da crise integram um discurso de protesto, mais ou menos inclinado para propostas de solução. A instalação do medo tem uma vocação menor para propor do que Índice médio de felicidade, sendo, no entanto, uma resposta fortíssima aos mecanismos mais deletérios da crise. Num artigo de 2016, publicado na revista Vértice, António José Avelãs Nunes fala da necessidade de um projecto político alternativo, que assente na confiança 
no homem e nas suas capacidades, um projecto inspirado em valores e empenhado em objetivos que os «mercados» não reconhecem nem são capazes de prosseguir" (85-86). Se admitirmos que a literatura, na sua informalidade, em sentido lato, pode contribuir para esse projeto, teremos mais confiança na sua razão de ser, daremos talvez mais valor a estes objetos ainda discretos no panorama da literatura portuguesa contemporânea e seremos talvez mais optimistas do que George Steiner em $O$ Silêncio dos Livros, pois esses livros continuam audíveis num mundo que não pára de falar. ${ }^{3}$

\section{Referências bibliográficas}

FUKUYAMA, F. (2018), Identidades: A exigência de dignidade e a política do ressentimento, trad. M. Freitas da Costa, D. Quixote, Lisboa.

KELLY, J. R., IANONNE, N. E., MCCARTY, M. K. (2016), “Emotional Contagion of Anger is Automatic: An Evolutionary Explanation”, British Journal of Social Psychology, 55(1), pp. 182-190, https://www.doi. org/10.1111/bjso.12134.

MACHADO, D. (2013), Índice médio de felicidade, D. Quixote, Lisboa.

NUNES, A. J. A. (2016), "Neoliberalismo e democracia", Vértice, 179, Lisboa, pp. 83-101.

ZINK, R. (2012), A instalação do medo, Teodolito.

${ }^{3}$ Aludo ao título do livro de Susan Cain Quiet: The Power of Introverts in a World that can't Stop Talking, 2012. 